\title{
O CONHECIMENTO PEDAGÓGICO DO CONTEÚDO E O PROFESSOR DE GEOGRAFIA: INICIANDO A DISCUSSÃO
}

\author{
The pedagogical knowledge content and the geography teacher: starting \\ discussion
}

\author{
Valéria Rodrigues Pereira \\ Doutoranda em Geografia, PGE/Universidade Estadual de Maringá \\ Docente da UFMS/Três Lagoas \\ valeriaufms@gmail.com \\ Claudivan Sanches Lopes \\ Doutor em Geografia, Professor do PGE/Universidade Estadual de Maringá \\ claudivanlopes@gmail.com
}

Artigo enviado para publicação em 27/08/2018 e aceito em 08/05/2019

DOI: 10.12957/tamoios.2019.36900

\begin{abstract}
Resumo
A reflexão sobre a prática pedagógica no contexto da sociedade contemporânea, aliada ao conhecimento do profissional docente, consiste em um campo de investigação relativamente novo. Nas pesquisas que enfocam os saberes docentes, a abordagem sobre o Conhecimento Pedagógico do Conteúdo converge com a presente proposta de pesquisa por valorizar e relacionar o conteúdo da disciplina com a ação pedagógica do professor. A pesquisa pretende trazer indicações dos caminhos percorridos na trajetória dos professores, elucidando quais saberes são construídos e mobilizados no ensino da disciplina. Desse modo, o presente ensaio apresenta o início da discussão sobre o Conhecimento Pedagógico do Conteúdo e a profissionalidade do professor de geografia. Expõem-se o construto teórico da pesquisa, relativo aos saberes docentes e ao trabalho do professor, bem como o cenário de investigação. Em sequência, os procedimentos metodológicos referentes à pesquisa qualitativa são apresentados para situar o contexto e etapas da investigação. Nesse conjunto, as condições e desafios do ensinar geografia são colocados para refletir sobre o ser profissional professor de geografia na atualidade.
\end{abstract}

Palavras chave: Saberes docentes; Identidade profissional; Ensino de geografia.

\begin{abstract}
The reflection on pedagogical practice in the contemporary society context, combined with the knowledge the teaching profession, consist in a relatively new field of research. In the researches which focus on the teaching knowledge, the approach on Pedagogical Knowledge Content converges with the present proposal of research when valuing and relating the subject content with the teacher's pedagogical action. This research intends to bring indications of the paths traveled in the teachers' path, clarifying how the knowledge is built and mobilized in the subject taught. Consequently, the present essay shows the beginning of the discussion about the Pedagogical Knowledge of Content and the geography teacher's professionalism. The research theoretical construct related to the teaching knowledge and the teacher's work, as well as the research scenario. In sequence, the methodological procedures concerning qualitative research are presented to situate the context and stages of the research. In this set, the conditions and challenges of teaching geography are established to reflect about the professional being as a geography teacher nowadays.
\end{abstract}

Keywords: Teaching knowledge; Professional identity; Geography teaching. 


\section{Introdução}

A importância da educação para o avanço da sociedade é inegável, e a discussão sobre prática educativa aliada ao desenvolvimento profissional constitui tarefa de pesquisadores e educadores preocupados com a questão. O conhecimento do profissional docente representa um campo de investigação em que ainda há muito a descobrir e, principalmente na geografia, esse terreno foi pouco explorado.

Conforme Roldão (2007), o que distingue o professor de outros profissionais é a ação de ensinar, ou seja, de fazer o outro aprender. Para Tardif (2002, p. 36), o trabalho educativo constituído pela organização, escolhas e pela realização de diversas atividades de ensino revela um conjunto de saberes do professor proveniente de diferentes fontes e dá origem a um saber plural, "[...] oriundo da formação profissional e de saberes disciplinares, curriculares e experienciais".

A pesquisa, com professores de geografia pertencentes a contextos diferentes, anseia conhecer os processos de formação e da ação profissional por meio do Conhecimento Pedagógico do Conteúdo proposto por Shulman (2005), evidenciando os saberes docentes e a importância do ensino. Desse modo, o presente ensaio é fruto de investigações iniciais referentes à pesquisa de doutorado "O conhecimento pedagógico do conteúdo e o ensino de geografia: um estudo da prática docente", em andamento na Universidade Estadual de Maringá, para trazer indicações dos caminhos percorridos pelos professores de geografia, demonstrando quais saberes são construídos e mobilizados para ensinar.

A pesquisa, situada na escola pública, em cidades de unidades federativas diferentes e com realidades desiguais, importa para conhecer o processo de constituição da identidade profissional, refletir sobre ele e assinalar o conjunto teórico e prático próprio a esse ofício.

Este tex to está organizado em quatro partes. Na primeira apresenta-se o contexto teórico da pesquisa, enfatizando-se os saberes docentes e a profissionalidade do professor. A seguir, o recorte espacial e os procedimentos metodológicos são explanados para elucidar o cenário de investigação. A terceira seção traz uma breve discussão sobre campo e cidade, rural e urbano no ensino da disciplina e, finalizando, algumas considerações referentes às questões de pesquisa ressaltando parte dos problemas enfrentados na educação básica e na ação profissional do professor de geografia.

\section{Os saberes docentes e a profissionalidade do professor}

Um dos aspectos da profissão docente refere-se à dificuldade em distinguir o conjunto de conhecimentos que envolvem esse trabalho. Como afirma Gauthier et al. (1998), diferentemente de outras profissões nas quais esse conhecimento já faz parte de uma cultura social, a profissão de professor ainda não se apresenta de forma clara.

Atualmente, as pesquisas que enfocam os saberes da docência colocam o professor em destaque e buscam lançar luz sobre os processos constitutivos de sua profissionalidade. De modo oposto aos estudos anteriores que afirmavam ser o professor o responsável pelas dificuldades encontradas no campo da educação, o novo caminho ressalta a profissionalização da docência considerando as especificidades da profissão.

Conforme apontado por Grossman; Wilson; Shulman (2005), os estudos mais recentes não enfocam a relação entre o conhecimento do professor e o sucesso (ou o fracasso) dos estudantes, mas a exploração da natureza, forma, organização e o conteúdo do conhecimento do professor permitindo compreender como os profissionais traduzem o conhecimento de suas ciências: 
En lugar de tratar de encontrar relaciones entre el conocimiento del profesor y el logro del estudiante, los investigadores han centrado sus energías en la exploración de la naturaleza, forma, organización y contenido del conocimiento del profesor. Los investigadores que trabajan en esta área han encontrado que la enseñanza implica la traslación del conocimiento de la materia per se en conocimiento de la materia para la enseñanza. (GROSSMAN; WILSON; SHULMAN, 2005, p. 6).

O desenvolvimento da autonomia profissional consiste em desafio para o professor desde sua formação inicial e esse processo evolui quando há articulação do conhecimento teórico com o prático no espaço da escola, em um movimento de constante reflexão e ação. Para Cavalcanti (2008, p. 87), “[...] os cursos devem buscar envolver os alunos, futuros professores ou aqueles em exercício, durante toda a formação, na reflexão da necessidade e das possibilidades de se trabalhar na prática com os conhecimentos que estão construindo".

No entanto, Mizukami (2013, p. 23) alerta que a formação do professor começa antes da graduação, ou seja, na escola, que constitui o "[...] local de aprendizagem e desenvolvimento profissional da docência". Sob esse aspecto, observa-se, de modo geral, a carência de um olhar mais amplo sobre a escola, que a considere também como espaço de formação.

O conhecimento acadêmico do professor representa um aspecto importante na definição do processo de ensino-aprendizagem das disciplinas escolares, e sem dúvida a qualidade do ensino de geografia está atrelada à qualidade da formação do professor, mas, como já exposto por Tardif (2002), o saber da formação profissional não é o único conhecimento.

De acordo com Montero (2001, p. 190), o conhecimento do professor a respeito da matéria e a maneira como os conteúdos são trabalhados na sala de aula são temas de estudos ainda recentes, e nessa linha de investigação destaca-se Lee S. Shulman por assinalar no "paradigma perdido" a pouca importância dada ao conteúdo na formação do professor e a necessidade de superar essa perspectiva.

Shulman (2014) defende a existência de uma base de conhecimentos na constituição da profissão do professor e cita quatro fontes que sustentam essa base: a formação acadêmica nas áreas de conhecimento ou disciplinas; os materiais e o entorno do processo educacional; pesquisas no âmbito da educação; e a sabedoria que emerge da prática de ensino.

De forma breve, a primeira trata do conhecimento do conteúdo e se assenta na bibliografia, nos estudos acumulados na área de conhecimento e na produção acadêmica quanto à natureza da própria ciência. A segunda fonte, estruturas e materiais, compreende os elementos organizados com o objetivo de ensinar e aprender. Estes incluem currículos, materiais didáticos, sistemas e instituições educativas, documentos e normas de orientação ao ensino, além de sindicatos, a gestão e os recursos financeiros. A terceira fonte versa sobre os estudos e bibliografia direcionados à compreensão dos processos de escolarização, ensino e aprendizado, considerando os aspectos normativos, filosóficos e éticos da educação. A quarta fonte, a sabedoria da prática, pode ser considerada a mais complexa, pois requer maior trabalho de investigação e decodificação para traduzir os significados da sabedoria e experiência dos professores competentes.

$\mathrm{Na}$ constituição da base de conhecimentos para ensinar, o autor também reconhece sete categorias:

1. Conhecimento do conteúdo; 
2. Conhecimento pedagógico geral, com especial referência aos princípios e estratégias mais abrangentes de gerenciamento e organização de sala de aula, que parecem transcender a matéria;

3. Conhecimento do currículo, particularmente dos materiais e programas que servem como "ferramentas do ofício" para os professores;

4. Conhecimento pedagógico do conteúdo, esse amálgama especial de conteúdo e pedagogia que é o terreno exclusivo dos professores, seu meio especial de compreensão profissional;

5. Conhecimento dos alunos e de suas características;

6. Conhecimento de contextos educacionais, desde o funcionamento do grupo ou da sala de aula, passando pela gestão e financiamento dos sistemas educacionais, até as características das comunidades e suas culturas; e

7. Conhecimento dos fins, propósitos e valores da educação e de sua base histórica e filosófica.

Contudo, o autor dá atenção especial ao Conhecimento Pedagógico do Conteúdo, CPC ou PCK, do inglês "Pedagogical Content Knowledge", por entender que essa categoria permite identificar os corpos distintos de conhecimento, combinando o conteúdo específico à pedagogia. $\mathrm{O}$ CPC é a capacidade de transformar o conteúdo a fim de ensinar de acordo com seu campo de atuação, com os objetivos de ensino e com as capacidades dos alunos no espaço da sala de aula:

[...] Representa la mezcla entre materia y didáctica por la que se llega a una comprensión de cómo determinados temas y problemas se organizan, se representan y se adaptan a los diversos intereses y capacidades de los alumnos, y se exponen para su enseñanza. (SHULMAN, 2005, p. 11).

Por combinar o conteúdo da disciplina com a ação pedagógica do professor, o CPC possibilita diferenciar um especialista da matéria de um professor, pois este se relaciona diretamente com a matéria a ser ensinada e essa capacidade de ensinar é que caracteriza o trabalho docente.

Shulman (1986, p. 9) ressalta o CPC como uma das formas mais úteis na representação do conhecimento por meio de comparações, ilustrações, exemplos, explicações, demonstrações e sintetiza esse conhecimento nas formas de representar e formular o assunto da matéria para torná-lo compreensível aos outros. Corroborando essa ideia, Lopes; Pontuschka (2015, p. 79) assinalam que esse conhecimento possibilita "[...] tornar o conteúdo de ensino atraente, acessível e útil aos alunos".

Gess-Newsome (1999), em continuidade à proposta de Shulman, indica o conhecimento disciplinar, o conhecimento pedagógico e o do contexto na formação do CPC, e para García (1999) o "contexto" sobressai por representar um dos componentes dos conhecimentos que os professores devem ter sobre o local e sobre as pessoas para quem ensinam:

É necessário que os professores estejam sensibilizados para conhecer as características socioeconômicas e culturais do bairro, as oportunidades que oferece para ser integrado ao currículo, as expectativas dos alunos etc. Esse tipo de conhecimento também inclui o conhecimento da escola, da sua cultura, dos professores e das normas de funcionamento. (GARCÍA, 1999, p. 91).

Todos os professores de forma mais elaborada ou não possuem saberes para seu ofício, e as experiências de formação, as práticas de ensino, os valores pessoais, o conhecimento do contexto de trabalho e a reflexão sobre os processos de ensino e 
$\overline{\text { aprendizagem originam um Conhecimento Pedagógico do Conteúdo que caracteriza cada }}$ profissional.

Será possível reconhecer características comuns existentes entre profissionais que atuam em lugares e em condições diferentes? Quais seriam essas características? Além disso, qual é o CPC quando são abordados os conteúdos geográficos, particularmente aqueles que envolvem a relação campo-cidade? A pesquisa procura essas respostas para reconhecer os saberes construídos e mobilizados pelo professor, conforme será exposto a seguir.

\section{O lócus e os procedimentos metodológicos da pesquisa}

Para o desenvolvimento desta proposta, escolhemos a pesquisa qualitativa, evidenciada pela observação, entrevista, interação constante com o objeto pesquisado e ênfase no processo de investigação. Segundo Bogdan; Biklen (1994), a investigação qualitativa geralmente possui cinco características que apresentam maior ou menor expressividade, a saber:

1. A fonte direta de dados é o ambiente natural, constituindo o investigador o instrumento principal;

2. A investigação qualitativa é descritiva;

3. Os investigadores qualitativos interessam-se mais pelo processo do que simplesmente pelos resultados ou produtos; indutiva;

4. Os investigadores qualitativos tendem a analisar os seus dados de forma

5. O significado é de importância vital na abordagem qualitativa.

Dentre estas características, duas se acentuam no presente estudo: a primeira, o ambiente natural é fonte direta de pesquisa, no caso o local de trabalho do professor - a escola - e a terceira, os investigadores interessam-se mais pelo processo do que simplesmente pelos resultados ou produtos, pois a busca pela compreensão do Conhecimento Pedagógico do Conteúdo do professor de geografia tem por substância considerar o conjunto de processos formativos que envolvem a prática do professor e seu caráter em construção.

Como pesquisa qualitativa, a proposta também se configura em estudo de caso visando a compreender uma realidade específica, ressaltar o conhecimento particular e ao mesmo tempo o contexto e as inter-relações que envolvem o grupo pesquisado (ANDRÉ, 2000). Para Shulman (2005), os estudos de caso são relevantes, pois a partir deles tornase possível conhecer a prática docente em situações reais, permitindo uma codificação do saber:

Las descripciones pormenorizadas del profesor experto son escasas. Si bien existen muchas caracterizaciones del profesor efectivo, la mayoría de ellas se concentra en la forma en que el profesor gestiona el aula. Se encuentran pocas descripciones o análisis de docentes en las que se preste especial atención no sólo al manejo de los alumnos en clase, sino además al manejo de las ideas en el aula. Será preciso poner el acento en ambos aspectos si se pretende que nuestras descripciones de una buena docencia sirvan como criterios de orientación suficientes para el diseño de una mejor educación. (SHULMAN, 2005, p. 2).

Outro componente fundamental nesse estudo é o sociopolítico/cultural, que se refere ao contexto sociopolítico e cultural mais amplo, ou seja, aos determinantes 
macroestruturais da prática educativa. Nessa ótica, a compreensão inclui a análise da relação entre condições históricas socialmente construídas no mundo do trabalho, majoritariamente decorrentes na atualidade das imposições do capital, apontado por Azzi (1999, p. 38) como um dos pressupostos para se compreender o trabalho docente "[...] no contexto da organização escolar e da organização do trabalho no modo de produção, no caso o capitalista".

Diante disso, considera-se o contínuo processo de construção e reconstrução da profissionalidade do professor frente a inúmeros fatores que interagem e influenciam em sua formação e prática de ensino. Assim, conhecer e analisar os documentos que embasam a prática docente nas escolas estaduais, tal como o currículo da disciplina, também integra os procedimentos de pesquisa.

Os participantes do estudo estão inseridos em diferentes situações de trabalho, mas isso não significa que constituam um grupo isolado, desvinculados de um contexto maior; ao contrário, estão diretamente ligados a outros contextos formados por condições sociais, políticas, econômicas e culturais que se desenvolvem em diversas escalas. Para Gamboa (2007, p. 103-104), as recentes pesquisas no campo da educação, em abordagens ou fenomenológicas ou dialéticas, colaboram, entre outros aspectos, para a recuperação dos contextos sociais e das condições históricas dos fenômenos educativos.

A opção por professores egressos do curso de Geografia da Universidade Federal de Mato Grosso do Sul, Campus de Três Lagoas (MS), em exercício em escolas públicas na cidade onde o curso é ofertado e em municípios próximos foi o critério inicial adotado para a seleção dos participantes.

Em seguida, consideraram-se algumas indicações feitas por professores e acadêmicos sobre os profissionais que desenvolvem um bom ensino na educação básica; posteriormente, procedeu-se ao diálogo e à escolha daqueles que se identificam com a proposta de investigação. Nesta fase, recorremos a Nóvoa (2009) por assinalar cinco enfoques que definem o bom professor: conhecimento, cultura profissional; tato pedagógico; trabalho em equipe e, compromisso social. Dentre esses, para este ensaio, ressaltamos o desenvolvimento da cultura profissional, para compreender a função da escola e aprender com os professores mais experientes,

[...] É na escola e no diálogo com os outros professores que se aprende a profissão. O registo das práticas, a reflexão sobre o trabalho e o exercício da avaliação são elementos centrais para o aperfeiçoamento e a inovação. São estas rotinas que fazem avançar a profissão. (NÓVOA, 2009, p. 30).

O objetivo é trabalhar com professores experientes, com mais de cinco anos de profissão, situados nas fases de estabilização e de diversificação, conforme proposto por Huberman (2000), nos ciclos da vida profissional. A escolha dos profissionais na fase de estabilização deve-se ao fato de não se situarem no período de exploração, quando ainda estão se reconhecendo e se adaptando ao trabalho; e, quanto aos professores na fase de diversificação, a escolha se faz considerando que o tempo acumulado na profissão possibilitou diversas experiências profissionais e enriquecimento teórico-prático. É importante frisar: a escolha desse critério não é uma regra de buscar classificar os profissionais, pois, como explica o próprio autor, o desenvolvimento profissional docente não é linear, nem um processo idêntico para todos os professores.

$\mathrm{Na}$ primeira etapa de pesquisa, as entrevistas do tipo semiestruturadas são o principal meio para dialogar com os docentes, tendo em vista que se iniciam com "[...] questionamentos básicos, apoiados em teorias e hipóteses, que interessam à pesquisa, e que, em seguida, oferecem amplo campo de interrogativas, fruto de novas hipóteses que vão surgindo à medida que se recebem as respostas do informante" (TRIVIÑOS, 1987, 
p. 146). Os temas da entrevista dividem-se entre as trajetórias pessoal, formativa e profissional, enfocando o percurso de formação e suas fontes.

Desse modo, o grupo de professores está composto por quatro participantes que trabalham nas cidades de Três Lagoas, em Mato Grosso do Sul, e, no estado de São Paulo, em duas cidades, Castilho e Pereira Barreto (Figura 1).

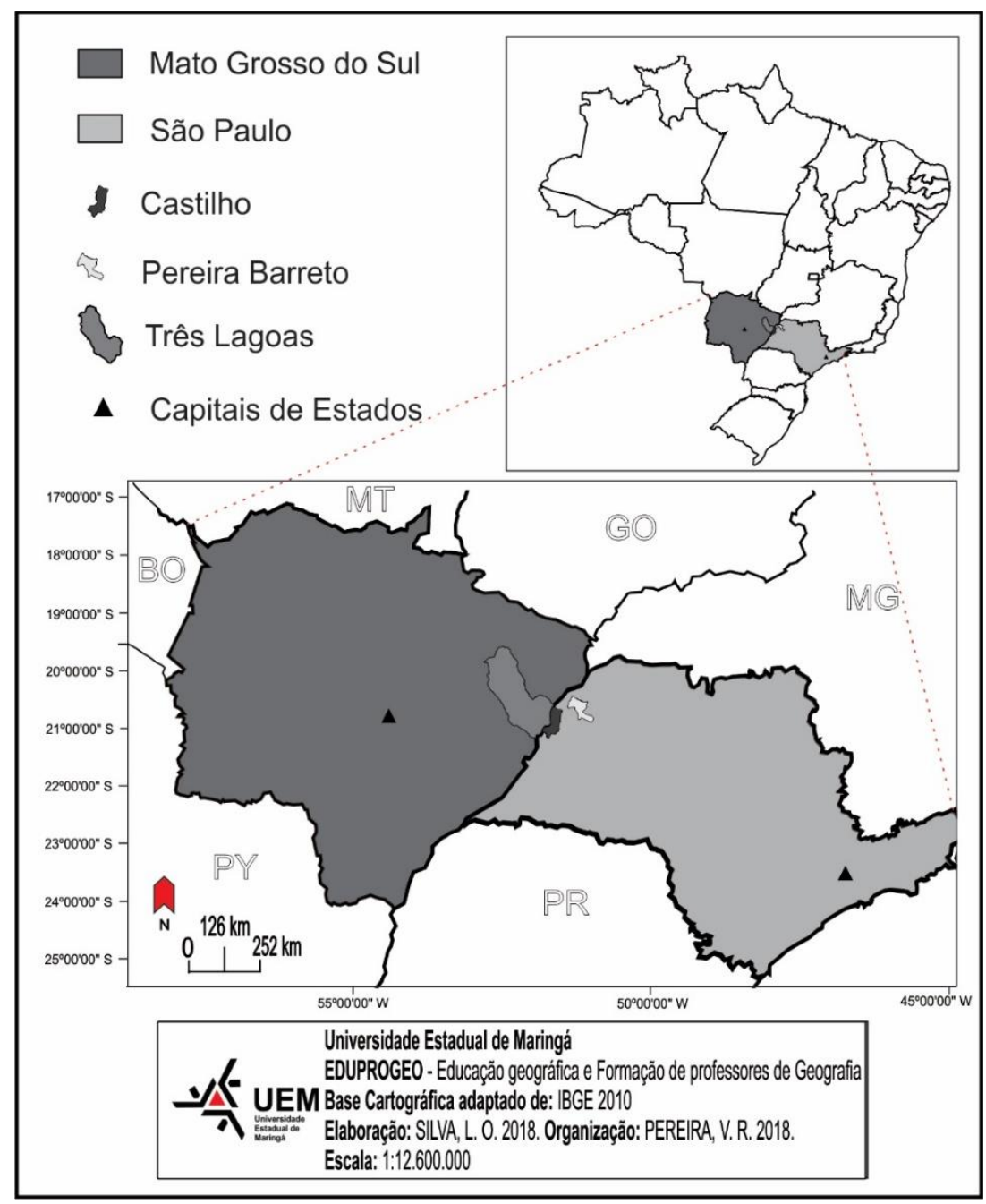

Figura 1: Localização dos municípios inseridos na área de pesquisa

A proximidade das cidades não significa que possuem características idênticas, pois apresentam relativa diversidade quanto aos aspectos sociais, educativos e às atividades produtivas. Com relação às escolas, a área da pesquisa compreende as quatro unidades em que cada professor participante trabalha. Localizadas em áreas centrais urbanas, essas escolas pertencem à rede estadual de ensino, oferecem ensino fundamental e ensino médio e, em duas delas, educação para jovens e adultos. Contudo, os planos de carreira, currículos, salários e a rotina do trabalho escolar são diferentes, conforme orientações das Secretarias de Educação às quais estão subordinadas: Secretaria da Educação de Mato Grosso do Sul (SED/MS) e Secretaria de Estado da Educação de São Paulo (SEE/SP).

Os participantes da pesquisa são egressos do curso de Geografia da Universidade Federal de Mato Grosso do Sul, Campus Três Lagoas/MS, mas possuem história pessoal e profissional distintas, são dois professores e duas professoras, conforme descrevemos a seguir utilizando nomes fictícios: 
-Professora Marisa: Inicialmente aspirava ser jornalista, mas mudanças na esfera familiar a levaram para geografia e após os primeiros anos de graduação sentiu que havia encontrado seu caminho. Com quase vinte anos na profissão, é professora efetiva desde o início da carreira. Em sua vida acadêmica interessava-se mais pelas questões ambientais, porém, com o passar do tempo, o trabalho na escola a fez olhar mais para as temáticas voltadas para as disparidades socioespaciais características da sociedade contemporânea. Tal interesse pode ser atribuído ao papel dos professores que considerou mais especiais em sua jornada de formação: ao contribuírem para as reflexões acerca das desigualdades e por sua experiência quando aluna da educação básica, pois naquele período sentia-se discriminada por ser pobre e negra. Assim, vislumbrou nos estudos a oportunidade de crescer e se destacar. Os professores mais significativos em sua vida foram aqueles que, além de conhecimento, dispensavam atenção a todos os alunos sem distinção e demonstravam posicionamento crítico. A professora Marisa gosta de estudar, procura participar de cursos de aperfeiçoamento e ainda almeja fazer o mestrado em geografia. Considera que a graduação não a preparou plenamente para ser professora, pois deu-lhe conhecimento teórico na área, mas faltou a pedagogia. Atualmente leciona em uma escola pública de ensino fundamental e ensino médio, em jornada de quarenta horas semanais. Ela demonstra carinho e preocupação com seus alunos e diz que é preciso ter sempre um "olhar mais humano" sobre os jovens, pois há muitos deles com diferentes problemas sociais, econômicos e familiares.

-Professor Gabriel: De formação mais recente, o professor Gabriel tem menos de dez anos na profissão. Antes da licenciatura, trabalhou como atendente em estabelecimentos comerciais do setor de alimentos. Sua família colaborou e apoiou a escolha do curso de geografia e no ensino médio ele já tinha afinidade com as ciências humanas. Na graduação foi bolsista e, apesar de dificuldades financeiras, pôde participar de diversas atividades proporcionadas pela universidade, como a vivência nos laboratórios e projetos e a participação em eventos locais, regionais e nacionais. Desde esse período e até o momento atual, interessa-se pela geografia urbana e sente que a faculdade o preparou mais para ser geógrafo do que professor. Lembra das boas práticas de ensino e da conduta dos professores que admirou na escola e na faculdade, e hoje em suas aulas isso está presente, em algumas falas, estratégias e na abordagem dos conteúdos. Docente concursado, atua em duas escolas, uma particular e outra pública, para turmas do ensino fundamental e do ensino médio, totalizando 52 horas semanais. Na escola pública, são 33 aulas em sala de aula com alunos e dez aulas de hora atividade, e na escola particular, são nove aulas. O professor comenta com entusiasmo o convívio escolar com seus alunos, especialmente com os alunos da unidade estadual e, apesar das diferenças, gosta do mesmo modo das escolas onde trabalha e diz que desde quando começou a dar aulas já mudou várias coisas em sua prática, seja para ensinar ou com relação à gestão da sala.

-Professor Paulo: Professor há cinco anos. Durante a educação básica, foi aluno de escola pública e depois mudou para escola privada. De vivência católica, antes de escolher a geografia, pretendia fazer teologia e tornar-se padre, mas ao final do ensino médio, o bom desempenho na disciplina e o fato de avistar no curso a presença de disciplinas que mais lhe interessavam o fizeram optar pela geografia. Os professores que o marcaram foram aqueles que demonstravam ter domínio de conhecimento, - o modo claro como trabalhavam o conteúdo -, postura, senso de justiça e bom humor. Durante a graduação, foi bolsista e participou de vários projetos de pesquisa, ensino e extensão, bem como de eventos nacionais. Com mestrado em geografia concluído, sua área de interesse envolve os estudos urbanos e do território. Atualmente é professor concursado, finalizando o período de estágio probatório pela Secretaria de Educação do Estado de São 
Paulo, mas lembra que as primeiras aulas como docente substituto em uma escola pública não foram fáceis e se perguntava onde estava a pedagogia. $\mathrm{O}$ professor tem uma carga horária de 57 horas semanais, com aulas no ensino fundamental, ensino médio e educação de jovens e adultos, sendo 34 horas semanais na escola pública e 23 aulas no ensino particular. Ele demonstra satisfação com a profissão que escolheu, expressa alegria e respeito pelas pessoas, busca uma conduta ética, separando os problemas externos dos do trabalho e procura cultivar um bom relacionamento com alunos e colegas de trabalho.

-Professora Daniela: Com pouco mais de cinco anos na profissão, a professora Daniela, quando estudante da educação básica, também passou pela escola particular e depois foi para escola pública. Ela lembra que essa mudança não ocorreu de forma tranquila, pois fez todo o ensino fundamental na mesma escola e, ao ser transferida, sentiu a diferença de ensino, alunos, estrutura e até de convivência proporcionada por essas unidades de ensino, mas com o passar do tempo adaptou-se à nova situação. Os professores que marcaram sua formação foram aqueles que demonstravam domínio do conhecimento dos conteúdos da matéria, mais afeto pelos alunos ou que ministravam as matérias de que ela gostava: no caso da educação básica, matemática e física. Essa afinidade com a área de exatas levou-a inicialmente a prestar vestibular para o curso de administração, porém isso não deu certo, e depois optou pela geografia, mesmo ouvindo vários comentários contrários a essa escolha. A conclusão do curso de geografia simboliza uma vitória, pois foi um processo com algumas interrupções por dificuldades familiares, de trabalho e greves que também a impediram de aproveitar melhor as atividades do curso. Ao iniciar-se na carreira docente, recorda com carinho o quanto a equipe da escola em que começou a apoiou com orientações, dicas e materiais de ensino. É professora concursada, está no final do período de estágio probatório no qual, além de passar por uma avaliação anual, precisa fazer cursos on-line e participar de encontros presenciais pela Secretaria da Educação do Estado de São Paulo. Seu cargo está em outra cidade, distante de seu local origem, e por esse motivo, no momento, optou por exercer sua função em cidade mais próxima, em outra escola também da rede de ensino estadual, mas pertencente ao Programa de Ensino Integral (PEI). Nessa unidade a professora tem jornada de quarenta horas semanais, distribuídas entre aulas com alunos e de trabalho pedagógico; além das aulas de geografia, ela ministra uma disciplina denominada eletiva, realizada em conjunto com outro professor, sobre uma temática indicada pelos próprios alunos e depois construída pelos professores.

A pesquisa com os professores está em desenvolvimento e a próxima etapa incluirá observações em sala de aula, focalizando as situações de ensino e aprendizagem referentes às temáticas: campo, cidade, rural e urbano. As observações serão do tipo estruturadas, quando as ações a serem observadas e a forma de registro são preestabelecidas, e não estruturadas, quando as ações dos sujeitos são apontadas da forma como acontecem, para compreender uma situação específica (ALVES-MAZZOTTI; GEWANDSZNAJDER, 1999, p. 164-166). Os registros da pesquisa serão analisados considerando Suzuki (2007), Marques (2002), Sposito (1996) e demais geógrafos que tratam da relação campo-cidade e conjuntamente interpretados segundo Bardin (1977) e Franco (2018) referente à análise de conteúdo, constituído, de modo sucinto, por organização da análise, codificação, categorização e inferência. A seguir esboçamos o referencial acerca da relação campo-cidade que será utilizado para a continuidade da investigação. 


\section{Campo e cidade na ação profissional do professor}

A discussão do espaço geográfico em perspectiva multiescalar em conjunto aos processos relacionados à intensa expansão capitalista, ao desenvolvimento do meiotécnico-científico-informacional à globalização, à predominância da sociedade urbanoindustrial, à definição de fronteiras e, ainda, ao lamentável aumento das disparidades socioespaciais reiteraram continuamente a necessidade de novas interpretações sobre os lugares. Na escola, tal fato solicita dos professores a contínua articulação do espaço vivido com o espaço produzido para compreender as espacialidades na contemporaneidade. Como afirma Oliveira (1994, p. 141), a compreensão do espaço geográfico busca “[...] desenvolver no aluno a capacidade de observar, analisar, interpretar e pensar criticamente a realidade tendo em vista a sua transformação".

Uma experiência de trabalho com alunos da educação básica e também com acadêmicos dos primeiros semestres da licenciatura em geografia mostrou, de modo preliminar, um entendimento equivocado sobre o que é campo e cidade. De modo geral, grande parte dos estudantes atribuiu atraso tecnológico para o campo, desenvolvimento econômico para cidade e demonstraram dificuldade em reconhecer e explicar a relação campo-cidade.

Contudo, campo e cidade, rural e urbano apresentam uma variedade de possibilidades para ensinar geografia. Estudantes que moram na cidade ou no campo carregam em sua história pretérita ou atual fortes laços com um desses espaços. Todavia, ainda hoje, não é raro campo e cidade serem ilustrados simplesmente sob a perspectiva de oposição, com a presença ou ausência de determinados elementos, apresentando diferenças nos tipos de atividades produtivas, na quantidade de habitantes, no nível tecnológico e na infraestrutura. Essa visão, segundo Marques (2002), legitimada também pelo poder público, determina o que é campo e o que é cidade estabelecendo um perímetro e, portanto, definindo áreas urbana e rural.

No Brasil, adota-se o critério político-administrativo e considera-se urbana toda sede de município (cidade) e de distrito (vila). Segundo o IBGE, é considerada área urbanizada toda área de vila ou de cidade, legalmente definida como urbana e caracterizada por construções, arruamentos e intensa ocupação humana; as áreas afetadas por transformações decorrentes do desenvolvimento urbano, e aquelas reservadas à expansão urbana (1999). (MARQUES, 2002, p. 97).

A autora lembra que, nessa classificação, não há preocupação em se reconhecerem as funções dos espaços e atribui-se, tal como acontece com o campo e a cidade, ao rural aquilo que não é urbano. Alentejano (2003, p. 314) acrescenta que rural e urbano não podem ser vistos de modo estrito pela ausência ou existência de determinadas características, mas "[...] enquanto a dinâmica urbana pouco depende de relações com a terra, tanto do ponto de vista econômico, como social e espacial, o rural está diretamente associado à terra, embora as formas como estas relações se dão sejam diversas e complexas".

A preocupação em compreender esses conteúdos e conceitos de forma integrada está presente em diversos trabalhos de geógrafos dedicados ou aos estudos agrários ou aos urbanos. Porém, de acordo com Fajardo (2009, p.110), há mais geógrafos urbanos envolvidos na discussão conceitual do papel do rural e do urbano.

Sob essa ótica, Sposito (1996, p. 64) acrescenta, na contemporaneidade, a preponderância do capitalismo na dinâmica espacial, porque "O modo de produção não 
produz cidades de um lado e campo do outro, mas ao contrário, esta produção compreende uma totalidade, com uma articulação intensa entre estes dois espaços”.

Para Lefebvre (2006), a cidade manifesta uma morfologia material e o urbano se constitui uma morfologia social e, apesar disso, ambos só podem existir e serem compreendidos de forma associada:

[...] a cidade, realidade presente, imediata, dado prático-sensível, arquitetônico - e por outro lado o "urbano", realidade social composta de relações a serem concebidas, construídas e reconstruídas pelo pensamento. Todavia, essa distinção se revela perigosa e a denominação proposta não é manejada sem riscos. O urbano assim designado parece poder passar sem o solo e sem a morfologia material [...] "o urbano" não pode dispensar uma base prático- sensível, uma morfologia. (LEFEBVRE, 2006, p.49).

Alentejano (2003) também argumenta que é imperativo superar as analogias feitas entre o campo atrasado e natural e a cidade como símbolo da modernidade e da indústria. Um espaço não exclui o outro, pois constituem "[...] um fenômeno mais complexo, onde um novo urbano e um novo rural surgem do choque entre ambos" (p.13). Para o autor a discussão atual deve ser expandida considerando o próprio modelo de desenvolvimento adotado no país que ecoa tanto nos processos agrários quanto nos processos urbano-industriais.

Complementando essa reflexão, Suzuki (2007) cita o papel do modo de produção capitalista na reconfiguração da função e forma da cidade e do campo, modificando relações sociais e de trabalho:

\footnotetext{
Para nós, há necessidade de se redefinir campo e cidade e rural e urbano à luz das transformações da sociedade brasileira, dos novos elementos da reprodução das relações sociais, inserindo como categorias essenciais a propriedade, o trabalho e o capital; o que nos permitirá superar leituras marcadamente quantitativas de definição de campo e de cidade e de rural e de urbano. (SUZUKI, 2007, p. 13).
}

Tradicionalmente o campo e a cidade no ensino de geografia para a educação básica foram ou ainda são abordados de maneira apartada. Os currículos e livros didáticos reforçam essa percepção e para exemplificar uma dessas ocorrências, o Referencial Curricular de Mato Grosso do Sul (MATO GROSSO DO SUL, 2012) traz, no quarto bimestre do primeiro ano do Ensino Médio, temas sob os títulos: "Produção Agropecuária", "Agricultura e Pecuária Brasileira" e "Políticas da terra"; e, no ano/série seguinte, o primeiro bimestre do segundo ano do Ensino Médio apresenta "Dinâmica Populacional", "População Brasileira" e "Etnia e cultura no mundo e no Brasil". Nesses exemplos, as competências e habilidades relacionadas à temática do campo consistem em: caracterizar e compreender os principais problemas do espaço agrário brasileiro (política ambiental, política agrária e movimentos sociais); compreender os processos de modernização agropecuária e suas repercussões e relacionar as formas de apropriação do espaço pelo homem e os problemas ambientais causados. E, as competências e habilidades relacionadas ao tema "População" envolvem observar tabelas, gráficos e mapas como meios de compreensão e estudo da dinâmica demográfica mundial e brasileira; identificar, compreender e discutir as principais mudanças na composição e distribuição da população mundial e brasileira.

Ora, tal organização revela de modo explícito o caráter tradicional e dicotômico na abordagem da relação campo-cidade. Nesse viés, o rural e urbano que deveriam 
aparecer conjuntamente em ambas temáticas não se apresentam de forma clara. Ao discutir o urbano e o rural, como resultante da divisão social e territorial do trabalho, consideram-se os diferentes processos econômicos, técnicos, sociais, políticos, históricos e culturais que abarcam tanto a cidade quanto o campo. Saquet (2006), corroborando a ideia tratada até aqui sobre a intrínseca relação entre o campo e a cidade, lembra que o rural não se define somente pela agricultura e nem o urbano pela indústria:

\begin{abstract}
Ambos relacionam-se reciprocamente e contêm uma miríade de aspectos específicos inerentes a formas de vida distintas. Há complexidade e heterogeneidade nos espaços rural e urbano. Elas são territoriais, com temporalidades e territorialidades. O que varia, são os arranjos, as intensidades, formas e conteúdos, as velocidades. Um só pode ser compreendido em suas relações com o outro, pois um está contido no outro, só vem a ser pelo outro, numa relação complementar, dialeticamente definida. (SAQUET, 2010, p. 160).
\end{abstract}

Ante o exposto, compete ao professor buscar meios de romper essa percepção para que os estudantes possam desenvolver a leitura espacial em sua totalidade. Todavia, o ato de ensinar buscando esse entendimento revela uma tarefa complexa e, para Castellar (1999), este é um dos desafios do ensino: saber escolher e organizar o trabalho docente, de modo que os conteúdos a serem trabalhados tenham significado para os alunos e possibilitem a construção do conhecimento:

\begin{abstract}
A decisão do conteúdo a ser trabalhado é do professor e esta decisão deve estar apoiada em uma análise do conhecimento já elaborado que se deseja ensinar. Os conteúdos escolares devem ser trabalhados articulados com o desenvolvimento das habilidades operatórias e dos conceitos, na perspectiva de fazer com que o aluno passe de um estado de menor conhecimento para um estado de maior conhecimento. (CASTELLAR, 1999, p. 53).
\end{abstract}

Amparando essa reflexão, Libâneo (1994, p. 16) afirma que o ofício do professor compreende "[...] dirigir, organizar, orientar e estimular a aprendizagem escolar dos alunos em função da condução do processo de ensinar, de suas finalidades modos e condições, que se mobilizam os conhecimentos pedagógicos gerais e específicos”.

Para Roldão (2007), tal como outros profissionais, o professor articula em cada situação todos os seus conhecimentos para ensinar e isso não acontece de forma aleatória:

[...] saber ensinar é ser especialista dessa complexa capacidade de mediar e transformar o saber conteudinal curricular (isto é, que se pretende ver adquirido, nas suas múltiplas variantes) - seja qual for a sua natureza ou nível -, pela incorporação dos processos de aceder a, e usar o conhecimento pelo ajuste ao conhecimento do sujeito e seu contexto [...]. (ROLDÃO, 2007, p. 101).

Assim, indaga-se: como os professores articulam esses conhecimentos para ensinar e como isso repercute na aprendizagem dos conteúdos geográficos quanto à relação campo- cidade? A próxima etapa da pesquisa segue na direção de compreender como se elabora e desenvolve o ensinar geografia na escola, identificando o repertório de saberes apropriados, construídos e mobilizados pelos professores de geografia.

Até o presente, de forma sucinta, constatou-se o trabalho dos profissionais buscando realizar a aproximação entre conteúdos teóricos e a realidade vivida, com uso de exemplos do cotidiano, seja da escola, da cidade, da região ou até aqueles divulgados pelos meios de comunicação. As experiências que envolvem a trajetória de trabalho dos familiares dos estudantes e as atividades produtivas desenvolvidas localmente ou no 
entorno, também entram no conjunto de abordagens utilizadas pelos professores para promover esse diálogo. Discussões sobre as mudanças que aconteceram no campo e na cidade, particularmente aquelas que atingiram diretamente a população e a produção em consequência do desenvolvimento econômico, causado pela expansão capitalista, via uso de tecnologias, constituem temas em que a relação campo e cidade ganhou destaque. Nesse sentido, os professores demonstraram o conhecimento do assunto da matéria, das características do local onde atuam e considerou os alunos nessas abordagens ao permitir e incentivar a participação durante as aulas, com contribuições sobre algum fato relacionado a matéria ou expondo dúvidas.

A pesquisa segue no propósito de relacionarem os saberes com a formação inicial e continuada, com o contexto da prática, reconhecendo o Conhecimento Pedagógico do Conteúdo dos professores, para contribuir com as reflexões acerca da profissionalidade docente e do atual papel do ensino de geografia na educação básica.

\section{Algumas considerações}

Este ensaio teve por finalidade iniciar a discussão sobre o Conhecimento Pedagógico do Conteúdo e a profissionalidade do professor de geografia. Como mencionado, os estudos anteriores afirmavam ser o professor o responsável pelas dificuldades encontradas no campo da educação, porém esta condição foi superada nas últimas décadas pela perspectiva de se ressaltarem os saberes profissionais do professor.

Colocar em relevo os conhecimentos do professor, por meio da análise das práticas de ensino, no espaço da escola, dialogando com os referenciais teóricos, importa para o conhecimento e reflexão sobre o processo de constituição de sua identidade profissional. Ademais, contribui para desmistificar a imagem de que as pesquisas acadêmicas são distantes da realidade e com pouca contribuição para o trabalho docente.

Outro aspecto levantado no texto é a compreensão do campo, da cidade, do rural e do urbano e como esses conceitos e categorias refletem a relação campo-cidade. Assim, compete ao professor propiciar condições de aprendizagem sobre a temática, rompendo com visões dicotômicas tão arraigadas no imaginário da sociedade e, consequentemente, dos alunos.

Evidentemente a construção da autonomia na profissão do professor não é trabalho simples. De certo modo, parece um caminho solitário, marcado por erros, acertos, alegrias e frustrações. O exercício docente em sua fase inicial, como bem apontado por Huberman (2000), é um grande descobrir, com inúmeras situações que a grande maioria não foi preparada para enfrentar. Com o passar do tempo, os anos de experimentação, estudo, conhecimento dos diversos elementos e atribuições que permeiam o cotidiano na escola possibilitam ao professor navegar de modo mais tranquilo.

Entretanto, esse navegar não acontece em águas de calmaria, pois o trabalho educativo objetiva a todo instante direcionar o olhar dos alunos para a aprendizagem. $\mathrm{O}$ professor conduz esse barco e a maneira como o faz representa, entre outros aspectos, o conhecimento da disciplina, da pedagogia e do contexto, ou seja, reflete um conhecimento pedagógico do conteúdo.

O cotidiano do trabalho educativo caracteriza-se por aspectos favoráveis e desfavoráveis. Em uma escala maior, há diversas vozes políticas que levantam a bandeira pela educação, mas que pouco contribuem para uma melhora significativa. Entretanto, em uma escala menor, de modo favorável no espaço da escola, o apoio da gestão escolar às propostas de ensino do professor, a disponibilidade de recursos materiais - tais como multimídia, livros didáticos, atlas, lousa branca e digital -, os espaços diferenciados para 
as aulas - como sala de informática e biblioteca -, as reuniões coletivas para estudo e preparação de aulas, os alunos participativos e a existência de comunicação entre os pares da disciplina nos fazem acreditar que a educação está em evolução. Sob outro ângulo, há professores que trabalham em escolas com pouco tempo e espaço para reflexão educativa, exigências de cumprimento de normas e prazos, salários defasados, ausência de formação continuada específica, alunos desinteressados, problemas relacionados a drogas, violência e insegurança que repercutem na sala de aula e desvalorizam a profissão. Nesse complexo cenário, marcado por dicotomias e problemas que se entrelaçam, questiona-se: como os professores desenvolvem um bom ensino e como o CPC do professor lida com essas questões para conduzir a aula, particularmente referente ao conteúdo campocidade?

Em um momento em que a educação brasileira prioriza o ensino por competências e habilidades, o peso do conteúdo parece diminuir. Em algumas escolas, especialmente as públicas, há grande preocupação de organizar as aulas por meio de competências e habilidades sem possibilitar e/ou promover uma reflexão a respeito da natureza dos conteúdos a serem trabalhados.

No espaço da escola existem elementos que beneficiam e outros, em maioria, que dificultam a atividade educativa. No caso da geografia, a situação se agrava, pois a disciplina está entre os componentes com as menores cargas horárias e algumas vezes é vista, por uma parcela de alunos, como desmotivadora e de menor importância para a formação.

Acrescentam-se a esse cenário as discussões em torno de um novo currículo por meio de uma Base Nacional Comum Curricular (BRASIL, 2017) que trará repercussões na educação básica e ainda nos cursos de licenciatura. O novo documento, junto com outros dispositivos legais, como a Lei $13.415 / 2017^{1}$, representam entre outros fatores, a lamentável iniciativa do governo federal de reformar o ensino médio, colocam em segundo plano algumas disciplinas e talvez até com a possibilidade de a geografia ser excluída da formação básica dos estudantes.

Vesentini (2013, p. 220) alerta, há certo tempo, que vivemos em um período crucial, caracterizado pela necessidade de termos um sistema escolar mais eficiente, um ensino que garanta sua relevância para a formação do estudante e possibilite a compreensão do mundo atual; porém, para que isso ocorra, torna-se necessário, entre outros enfoques, analisar o contexto educacional e de trabalho docente, o papel dos conteúdos escolares, as práticas de ensino, a aprendizagem dos alunos, assim como os processos formativos do professor.

A aproximação entre professores e os territórios de formação e de ação torna-se necessária para estabelecermos uma comunicação para o enfrentamento dos problemas educacionais de hoje, os quais incluem as problemáticas do ensino de geografia na escola.

Shulman (2005), ao explicar as quatro fontes da base de conhecimento - a formação acadêmica nas áreas de conhecimento ou disciplinas, os materiais e o entorno do processo educacional, pesquisas no âmbito da educação e a sabedoria que emerge da prática do ensino, revela uma espécie de mapa para compreender os fatores e condições que fazem parte do profissional professor. Para a geografia, objeto desta reflexão, percorrer esse mapa significa descobrir como propiciar um bom ensino da disciplina, ressignificando seu papel na formação dos estudantes e da própria sociedade.

Dentre as categorias da base de conhecimento para ensinar, destaca-se o Conhecimento Pedagógico do Conteúdo por reunir o conhecimento disciplinar, o conhecimento pedagógico e do contexto, representando uma bússola que orienta esta pesquisa. O CPC é considerado neste trabalho como uma marca da profissionalidade docente, em que os conhecimentos estão em contínua articulação e movimento. A 
pesquisa em cenários diferentes permite vislumbrar entre os professores características em comum que se manifestam durante o processo de ensino e aprendizagem. Ao seguir por esse caminho tenciona discutir a profissionalidade do professor de Geografia e a licenciatura como essenciais para o ofício docente.

Previamente, este estudo considera a totalidade da trajetória profissional do professor, com o contexto de atuação e as especificidades educativas, somadas às experiências pessoais e profissionais, como partes que influenciam cotidianamente o trabalho docente e, concomitantemente, possibilitam desenvolver o Conhecimento Pedagógico do Conteúdo.

\section{Nota}

1 - Essa lei, conhecida como Reforma do Ensino Médio, representa um conjunto de alterações na Lei de Diretrizes e Bases da Educação, Lei no 9.394/1996 (BRASIL, 2017a), e tem sido objeto de inúmeras críticas de educadores, entidades sindicais e científicas.

\section{Referências}

ALENTEJANO, Paulo Roberto R. As relações campo-cidade no Brasil do século XXI. Revista de Políticas Públicas, São Luís, v. 7, n. 2, p. 303-328, jul/dez. 2003.

ALVES-MAZZOTTI, Alda J. GEWANDSZNAJDER, Fernando. O método nas ciências naturais e sociais: pesquisa quantitativa e qualitativa. 2. ed. São Paulo: Pioneira, 1999.

ANDRÉ, Marli. Etnografia da prática escolar. 5. ed. Campinas, SP: Papirus, 2000.

AZZI, Sandra. Trabalho docente: autonomia didática e construção do saber pedagógico. In: PIMENTA, Selma G. (Org.). Saberes pedagógicos e atividade docente. São Paulo: Cortez, 1999.

BARDIN, Laurence. Análise de conteúdo. Lisboa: Edições 70, 1977.

BOGDAN, Robert; BIKLEN, Sari. Investigação qualitativa em educação - uma introdução à teoria e aos métodos. Porto: Porto Editora, 1994.

BRASIL. Lei $\mathrm{n}^{\mathrm{o}}$ 13.145, de 16 de fevereiro de 2017. Altera a Lei $\mathrm{n}^{\circ}$ 9.394, de 20 de dezembro de 1996, que estabelece as diretrizes e bases da educação nacional. Brasília: MEC, 1996. Diário Oficial da União de 17/02/2017, p. 1. Disponível em: <https://www.planalto.gov.br/ccivil_03/_ato2015-2018/2017/lei/113415.htm> Acesso em: 16 jul. 2017 a.

BRASIL. Ministério da Educação. Base Nacional Comum Curricular (BNCC). Proposta preliminar. Terceira versão. Brasília: MEC, 2016. Disponível em: $<\mathrm{http}$ ///basenacionalcomum.mec.gov.br/documentos/bncc-2versao.revista.pdf $>$. Acesso em: 31 mai. 2017.

CASTELLAR, Sonia Maria V. A Formação de professores e o ensino de geografia. Terra Livre. As transformações do mundo da educação: Geografia, ensino e responsabilidade social. Revista da Associação dos Geógrafos Brasileiros, São Paulo, n. 14: p. 51-59, jan./jul., 1999.

CAVALCANTI, Lana de Souza. Formação inicial e continuada em geografia: Trabalho Pedagógico, metodologias e (re)construção do conhecimento. In: ZANATTA, Beatriz Aparecida; SOUZA, Vanilton Camilo de (Org.). Formação de professores: reflexões do atual cenário sobre o ensino da geografia. Goiânia: NEPEG, 2008. p. 85-102 
FAJARDO, Sérgio. A questão locacional na relação campo-cidade. Temas \& Matizes: Dossiê relações campo-cidade, n. 16, p. 97-114, segundo semestre de 2009.

FRANCO, Maria Laura Puglisi Barbosa. Análise de conteúdo. 5.ed. Campinas: Autores Associados Livro Editora, 2018.

GAMBOA, Silvio S. Pesquisa em Educação: métodos e epistemologias. Chapecó: Argos, 2007.

GARCÍA, Carlos Marcelo. Formação de professores para uma mudança educativa. Porto: Porto Editora,1999.

GAUTHIER, Clemont et al. Por uma teoria da pedagogia. Pesquisas contemporâneas sobre o saber docente. Ijuí: Editora Unijuí, 1998.

GESS-NEWSOME, Julie. Pedagogical Content Knowledge: an Introduction and Orientation. In: GESS-NEWSOME, Julie \& LEDERMAN, Norman G. (Eds.) Examining Pedagogical Content Knowledge. Dordrecht, Netherlands; Boston: Kluwer Academic Publishers, 1999. p. 3-17.

GROSSMAN, Pamela L; WILSON, Suzzane M; SHULMAN, Lee S. Profesores de sustancia: el conocimiento de la matéria para la enseñanza. Profesorado. Revista de currículum y formación del profesorado. Granada,España, v. 9, n. 2, , p. 1-25, 2005.Disponível em: < https://recyt.fecyt.es/index.php/profesorado/article/download/42833/24723>. Acesso em: 14 jun. 2017.

HUBERMAN, Michael. O ciclo de vida profissional de professores. In: NÓVOA, Antonio (Org). Vidas de professores. Porto: Porto Editora, 2000. p. 31-61.

LEFEBVRE, Henri. O direito à cidade. 4. ed. Tradução de Rubens Eduardo Frias. São Paulo: Centauro Editora, 2006.

LIBÂNEO, José Carlos. Didática. São Paulo: Cortez, 1994.

LOPES, Claudivan S.; PONTUSCHKA, Nídia N. O conhecimento pedagógico do conteúdo na prática profissional de professores de geografa. GEOUSP: Espaço e Tempo, São Paulo, v. 19, n. 1, p. 76-92, 2015.

MARQUES, Marta Inez Medeiros. O conceito de espaço rural em questão. Terra Livre, São Paulo, v. 18, n. 19, p. 95-112, jul./dez. 2002.

MATO GROSSO DO SUL (ESTADO). Referencial Curricular do Mato Grosso do Sul. SED/Mato Grosso do Sul, 2012.

MIZUKAMI, Maria da Graça Nicoletti. Escola e desenvolvimento profissional da docência. In: GATTI, Bernadete A. et al. Por uma política nacional de formação de professores. São Paulo: Unesp, 2013, p. 23-54.

MONTERO, Lourdes. A construção do conhecimento profissional docente. Lisboa: Instituto Piaget, 2001.

NÓVOA, Antonio. Professores: Imagens do futuro presente. Lisboa: Educa, 2009.

OLIVEIRA, Ariovaldo U. Educação e ensino de geografia na realidade brasileira. In: OLIVEIRA, Ariovaldo U. (Org.). Para onde vai o ensino de Geografia? 4. ed. São Paulo: Contexto, 1994. p.135-144. 
ROLDÃO, Maria do Céu. Função docente: natureza e construção do conhecimento profissional. Revista Brasileira de Educação, São Paulo, n. 34, v. 12, p. 94-103, 2007. Disponível em: <http://www.scielo.br/pdf/rbedu/v12n34/a08v1234.pdf〉. Acesso em: 19 set. 2016.

SAQUET, Marcos. Por uma abordagem territorial das relações urbano-rurais no Sudoeste paranaense. In: SPOSITO, Maria E. B.; WHITACKER, Arthur M. (Org.). Cidade e campo: relações e contradições entre urbano e rural. São Paulo: Expressão Popular, 2010. p. 157-186.

SHULMAN, Lee S. Conhecimento e ensino: fundamentos para a nova reforma. Cadernos Cenpec, São Paulo, v. 4, n. 2, p. 196-229, dez. 2014. Disponível em: <http://cadernos.cenpec.org.br/cadernos/index.php/cadernos/article/view/293/297>. Acesso em: 07 mar. 2017.

SHULMAN, Lee S. Conocimiento y enseñanza: fundamentos de la nueva reforma. Profesorado. Revista de currículum y formación del professorado. Granada, España, v. 9, n. 2, p. 1-30, 2005. Disponível em: http<://www.ugr.es/local/recfpro/rev92art1.pdf>. Acesso em: 03 set. 2016.

SHULMAN, Lee S. Those who Understand: Knowledge Growth in Teaching. Educational Researcher, v. 15, n. 4, p. 4-14, feb. 1986. Disponível em: $\langle$ http://www.fisica.uniud.it/URDF/masterDidSciUD/materiali/pdf/Shulman_1986.pdf $>$. Acesso em: 10 abr. 2014.

SPOSITO, Maria Encarnação B. Capitalismo e Urbanização. 7a . ed. São Paulo: Contexto, 1996.

SUZUKI, Julio César. Campo e cidade no Brasil: transformações socioespaciais e dificuldades de conceituação. Revista NERA, UNESP, v. 10, n. 10, p. 134-150, jan./jun. 2007.

TARDIF, Maurice. Saberes docentes e formação profissional. Petrópolis: Vozes, 2002.

TRIVIÑOS, Augusto Nibaldo S. Introdução à pesquisa em Ciências Sociais: a pesquisa qualitativa em educação. São Paulo: Atlas, 1987.

VESENTINI, José W. Realidades e perspectivas do ensino de Geografia no Brasil. In: VESENTINI, José W. (Org.) O ensino de geografia no século XXI. Campinas: Papirus, 2013. 